\title{
Normative Study of Rorschach (Parisian School) for Brazilian Adolescents ${ }^{1}$
}

\author{
Maria Luísa Casillo Jardim-Maran \\ Universidade de São Paulo, \\ Ribeirão Preto-SP, Brazil
}

\author{
Sonia Regina Pasian ${ }^{2}$ \\ Universidade de São Paulo, \\ Ribeirão Preto-SP, Brazil
}

\author{
Erika Tiemi Kato Okino \\ Universidade de São Paulo, \\ Ribeirão Preto-SP, Brazil
}

\begin{abstract}
Among the projective methods of psychological assessment, the relevance of the Rorschach method stands out in the investigation of personality, albeit without normative references in the Parisian School for adolescents in Brazil. This study addresses this gap by developing normative standards of the Rorschach method (Parisian School) for this age group, evaluating specificities of production associated with sex, age and school system. The Rorschach tests were individually administered to 180 students aged from 15 to 17 years old, with typical signs of development. Data considering the 54 Rorschach's variables were descriptively and inferentially examined. The main average results were: (a) productivity: $\mathrm{R}=17.7$; (b) modes of apperception: $\mathrm{G}=35.0 \%$, $\mathrm{D}=33.4 \%, \mathrm{Dd}=30.3 \%$ and $\mathrm{Dd}=1.1 \%$; (c) determinants and formal indexes: $\mathrm{F} \%=54.5 \%, \mathrm{~F}+\%=55.6 \%$ and $\mathrm{F}+\mathrm{ext} \%=57.3 \%$; (d) predominant content: $\mathrm{A} \%=51.0 \%$ and $\mathrm{H} \%=20.9 \%$; (e) Ban $=17.0 \%$. Specificities of production according to sex, age and school system were identified, which supports the analysis and interpretation of Rorschach's variables with contemporary Brazilian adolescents.
\end{abstract}

Keywords: Rorschach test, test norms, adolescents, projective techniques, personality

\section{Padrões Normativos do Rorschach (Escola de Paris) em Adolescentes do Brasil}

\begin{abstract}
Resumo: Dentre os métodos projetivos de avaliação psicológica, a relevância do Rorschach destaca-se na investigação da personalidade, embora sem referenciais normativos na Escola de Paris para adolescentes no Brasil. Esse estudo atende a essa lacuna, construindo padrões normativos do Rorschach (Escola de Paris) para essa faixa etária, analisando-se especificidades da produção associadas a sexo, idade e origem escolar. O Rorschach foi administrado individualmente a 180 estudantes de 15-17 anos de idade, com sinais de desenvolvimento típico, examinando-se descritiva e inferencialmente dados de 54 variáveis do método. Os principais resultados médios foram: (a) produtividade: $\mathrm{R}=17,7$; (b) modos de percepção: $\mathrm{G}=35,0 \%, \mathrm{D}=33,4 \%, \mathrm{Dd}=30,3 \%$ e $\mathrm{Dbl}=1,1 \%$; (c) determinantes e índices formais: $\mathrm{F} \%=54,5 \%, \mathrm{~F}+\%=55,6 \%$ e $\mathrm{F}+$ ext $\%=57,3 \%$; (d) conteúdos predominantes: A\% $\%=51,0 \%$ e H\% $=20,9 \%$; (e) Ban = 17,0\%. Foi possível identificar especificidades de produção em função de sexo, idade e origem escolar, embasando análise e interpretação das variáveis do Rorschach em adolescentes do Brasil no contexto contemporâneo
\end{abstract}

Palavras-chave: teste de Rorschach, normas do teste, adolescentes, técnicas projetivas, personalidade

\section{Estudio Normativo del Rorschach (Escuela de Paris) Para Adolescentes Brasileños}

\begin{abstract}
Resumen: Entre los métodos proyectivos de evaluación psicológica, la relevancia del Método de Rorschach se destaca en la investigación de la personalidad, aunque la ausencia de normas para la Escuela de Paris para adolescentes en Brasil. Este estudio desarrolló normas del Rorschach para este grupo de edad y evaluó la producción asociada con el sexo, la edad y la escuela. Fueron evaluados individualmente por Rorschach (Escuela de Paris) 180 estudiantes de 15-17 años de edad, con signos típicos de desarrollo, examinando descriptivo y por inferencia de datos 54 variables del método. Los principales resultados medios fueron: (a) rendimiento: $\mathrm{R}=17,7$; (b) modos de percepción: $\mathrm{G}=35,0 \%, \mathrm{D}=33,4 \%, \mathrm{Dd}=30,3 \%, \mathrm{Dbl}=1,1 \%$; (c) determinantes $\mathrm{y}$ índices formales: $\mathrm{F} \%=54,5 \%, \mathrm{~F}+\%=55,6 \%, \mathrm{~F}+\mathrm{ext} \%=57,3 \%$; (d) el contenido predominante: $\mathrm{A} \%=51,0 \%, \mathrm{H} \%=20,9 \%$; (e) Banalidades $=17,0 \%$. Fueran encontrados patrones específicos de respuesta como una función de el sexo, la edad y la escuela y, a partir de los resultados, es posible el interpretación de Rorschach en adolescentes en Brasil en el contexto contemporáneo.
\end{abstract}

Palabras clave: test de Rorschach, normas de test, adolescentes, técnicas proyectivas, personalidad

Among the projective projects of psychological tests used in Brazil and around the world, the Rorschach test

\footnotetext{
${ }^{1}$ Paper derived from the doctoral dissertation of the primary author under the supervision of the second author, defended in 2011, in the Graduate Program in Psychology at Faculdade de Filosofia, Ciências e Letras de Ribeirão Preto of the Universidade de São Paulo.

${ }^{2}$ Correspondence address:

Sonia Regina Pasian. Programa de Pós-graduação em Psicologia. Departamento de Psicologia, Faculdade de Filosofia, Ciências e Letras de Ribeirão Preto da Universidade de São Paulo. Av. Bandeirantes, 3900, Monte Alegre. CEP 14040901. Ribeirão Preto-SP, Brazil. E-mail: srpasian@ffclrp.usp.br
}

has achieved indisputable importance. This instrument to assess personality figures among those most frequently used on all continents, as its history shows with a sizeable and diverse body of research (Brando, Valera, \& Zarate, 2008; Jordão \& Ramires, 2010; Meyer, Erdberg, \& Shaffer, 2007; Meyer, Viglione, Mihura, Erard, \& Erdberg, 2011; Mihura, Meyer, Dumitrascu, \& Bombel, 2013; Nascimento, 2010). In addition to its international recognition in different fields of application, Rorschach presents evidence of validity in various sociocultural contexts and its potential to contribute scientifically to the understanding of the psychological 
structure and functioning of individuals is practically incontestable (Azoulay et al., 2007; Hisatugo \& Yazigi, 2014; Ikiz et al., 2010; Mihura et al., 2013; Nascimento, 2010; Pasian \& Loureiro, 2010; Viglione, Meyer, Mihura, Erard, \& Erdberg, 2012; Weiner, 1998/2000; Yazigi, 2014). The Rorschach test method helps access conscious and observable characteristics of personality but also reviews repressed and unconscious aspects (Rausch de Traubenberg, 1970/1998). It permits assessing individuals' current and latent resources, as well as vulnerable aspects. This global understanding can support psychological counseling, the prescription of therapies, or evolutionary prognosis (Chabert, 1998/2004).

Despite this sort of evidence, Meyer et al. (2007) acknowledge that the search for normative Rorschach references is a critical aspect in the processes of psychological assessment because of the empirical difficulties faced by studies of this nature in various countries. The development of normative studies addressing the diverse age ranges and theoretical approaches of Rorschach is essential and necessary to continually improve the test, and update positive indicators of validity and reliability. A review of the scientific literature in the field performed in the last ten years, however, revealed there is a lack of Brazilian normative studies based on the Rorschach Parisian School (Chagnon, 2013), especially those addressing the period of adolescence. Given changes in the sociocultural context over the course of recent decades, changes in terms of psychological dynamics are expected, which shows the importance of developing studies to update normative references to enable appropriate analyses of Rorschach indicators (and of other psychological assessment methods), specifically in this stage of human development.

According to Weiner (1998/2000), the proper use of the Rorschach method is necessarily based on updated empirical evidence derived from results obtained from reference groups, data that support the analysis and proper interpretation of the variables of this projective instrument for the particular individual results. Nascimento (2010) asserts that, in order to respond to Rorschach cards, one uses motivation derived from drive (individual aspects) and, at the same time, orientation and control, so that the expression is legitimate and in accordance with the standards of a given culture. Hence, the professionals using this method should be prepared to understand both individual personality and sociocultural elements that impact the pattern of one's responses.

To conduct a review of the scientific literature including normative studies concerning the Rorschach test developed at the beginning of the 21 st century, the PsycInfo, Pepsic and Lilacs databases were consulted for the period from 2000 to 2011 with the indexers Rorschach and Norms. A total of 38 studies were identified, the main theme of which was the development of norms for the Rorschach Method and among the different assessment systems, the Comprehensive System stood out. A concern of researchers from various countries was observed for the development of normative references to specific populations from various age ranges, which confirms the relevance of this type of scientific investigation to support appropriate clinical practice with the use of Rorschach tests. It is worth noting, however, that of the 38 studies found, only four address the specific period of adolescence; two of them (Lis, Salcuni, \& Parolin, 2007; Van Patten, Shaffer, Erdberg, \& Canfield, 2007) were published in the Journal of Personality Assessment and were based on the Rorschach Comprehensive System, while the other two (Azoulay et al., 2007; Ikiz et al., 2010) were published in Psychologie Clinique et Projective and follow the Parisian School's theoretical framework. The remaining studies focused on the results of children or adults, while none was developed in Brazil or involved adolescents.

The peculiarities of the cognitive and affective development of adolescents, of the transition in the way they relate to family in regard to achieving incisive social gain, are linked to intensive body changes and may or may not culminate in adaptive difficulties (Carvalho \& Novo, 2014; Knobel, 1981; Outeiral, 1994; Paladino, 2005). The search to construct an identity tends to be central at this point, since they need to ensure greater independence and autonomy. At the same time, according to Paladino (2005), the adolescent does not have substantial emotional experience and may seek isolation and let reason prevail as a way to protect his/her affections. The use of psychological assessment instruments to investigate affective experiences and internal movements experienced by adolescents, though complex and directly linked to the individuals' sociocultural context, can contribute to the understanding of this stage of development and enable the identification of traits and characteristics of adolescence.

Given this context and the lack of Brazilian studies addressing adolescents according to the Parisian School and the growing clinical demand for specific normative references, this study intends to help fill in this gap. Its main objective is to develop normative standards for the Rorschach method according to the assessment system of the Parisian School, addressing Brazilian adolescents to characterize their pattern of responses to this projective method (productive indexes; distribution of locations, determinants and content of responses; and types of affective experiences) in order to enable the appropriate use of this instrument in psychological assessment processes in the current context, in addition to meet the guidelines of the Brazilian Federal Council of Psychology (CFP, 2010) and Primi (2010).

\section{Method}

\section{Participants}

A total of 180 adolescents, of both genders, aged between 15 and 17 years old, regularly enrolled in public or private schools in the interior of São Paulo, Brazil participated in the study. According to the objectives, adolescents with typical developmental indicators, in both physical and psychological terms, were assessed through an interview and the application of a questionnaire addressing personal history that was developed by the researchers and answered by the parents. Exclusion criteria were: academic delay, apparent 
and/or reported sensory disabilities, symptoms or signs of psychiatric or psychological disorder in the last year.

Participation was voluntary and authorized by the parents or legal guardians. The individuals were equally distributed according to age, gender, and pattern of socioeconomiccultural experiences (based on school system: public or private), as recorded in Table 1.

Table 1

Characterization of the Sample of Adolescents $(N=180)$, According to Sex, Age and School System

\begin{tabular}{lcccccc}
\hline & $\begin{array}{c}\text { School } \\
\text { System }\end{array}$ & \multicolumn{2}{c}{ Public School } & \multicolumn{2}{c}{ Private School } & \\
\cline { 2 - 5 } Age & Female & Male & Female & Male & \\
\hline 15 years old & 15 & 15 & 15 & 15 & 60 \\
16 years old & 15 & 15 & 15 & 15 & 60 \\
17 years old & 15 & 15 & 15 & 15 & 60 \\
TOTAL & 45 & 45 & 45 & 45 & 180 \\
\hline
\end{tabular}

A convenience sample was composed of volunteers from schools that authorized the study on their premises and was numerically sufficient to meet the study's objectives. Note that sex, age, and school system are important variables in the production indicators in the Rorschach Method, as stressed in the scientific literature (Weiner, 1998/2000), and were, therefore, considered in the sample composition in order to enable the appropriate analysis of empirical data.

\section{Instruments}

Informative Questionnaire (IQ). Developed for this study, with questions addressing the students' personal and academic development. The questionnaire was delivered to the parents of the potential participants to support the process of selecting volunteers.

Rorschach Method (Parisian School). Applied and assessed according to Anzieu (1970/1986) and Rausch de Traubenberg (1970/1998), with the use of standardized cards, record sheets, and location of responses. This approach has positive psychometric indicators as reported by Pasian (2000) in Brazil, by Azoulay et al. (2007) in France and Ikiz et al. (2010) in Turkey.

\section{Procedure}

Data collection. Data collection was conducted by five psychologists with prior experience in psychological assessment and the Rorschach Method (Parisian School), in order to ensure the homogeneity of procedures and case analysis. This methodological caution enhanced accuracy and met international guidelines for research using the Rorschach Method (Weiner, 1998/2000).

The primary author invited the adolescents to participate in the study during school hours in the respective teaching institutions, the occasion during which the study's objectives and data collection were presented. Those who showed interest received free and informed consent forms and an
Informative Questionnaire to be filled out by themselves and/or their parents or legal guardians. Data were collected during school hours with the consent of teachers in adapted classrooms (in terms of lighting and privacy) provided by the respective schools. The Rorschach Method was applied individually in one session of approximately 60 minutes after instructions as standardized by the Parisian School (Rausch de Traubenberg, 1970/1998) were provided.

Data analysis. The classification of responses provided to the Rorschach Method was performed according to the technical standards of the Parisian School (Anzieu, 1970/1986; Azoulay et al., 2007; Ikiz et al., 2010; Rausch de Traubenberg, 1970/1998) and the normative reference by Pasian (2000). Given the accuracy of coding and the fact that this stage of the study had the collaboration of nine psychologists, specific training was provided for the classification of responses. After obtaining the necessary level of agreement among the nine evaluators, each Rorschach protocol was then independently assessed by the examiners. After the protocols' coding process was finalized, the index of accuracy among the study examiners was calculated in accordance with Fensterseifer and Werlang (2008) and Weiner (1998/2000). For that, 36 protocols were selected from the sample ( $20 \%$ of the total of cases) and the percentage of agreement among the independent examiners was calculated by dividing each response into four categories of classification: location, determinant/formal quality, content and banality. The following agreement was reached: (a) Locations $=96 \%$; (b) Determinants $=88 \%$; (c) Content $=$ $92 \%$; (d) Banalities $=92 \%$. Note that the index of agreement among the independent evaluators was greater than $80 \%$, which is considered satisfactory by Weiner (1998/2000).

The final coding of the protocols of Rorschach Psychodiagnostic tests were inserted in a database developed in Microsoft Office Excel 2007. Spreadsheets compatible with the procedures PROC REG, PROC LOGISTIC and PROC FREQ available in the Statistical Analysis System (SAS), version 9.1, were developed to verify the potential effects of sociodemographic variables (sex, age and school system). This procedure enabled descriptive and inferential analysis in which a level of significance at $p \leq .05$ was adopted. The following analyses were conducted:

1. Descriptive statistics, i.e., mean, standard deviation, median, and minimum and maximum values of the main variables of the Rorschach test according to the Parisian School were calculated for a set of participants $(N=180)$ (general profile of results): R, RA, Refusal, Denial, mean elapsed time (TLm) and mean Reaction time (TRm) (variables related to productivity and rhythm); G, D, Dd, Dbl, $\mathrm{Di}$ (modes of apperception); F+, F+/-, F-, $\Sigma \mathrm{F}, \mathrm{K}$, kan, kp, kob, $\Sigma \mathrm{k}, \mathrm{FC}, \mathrm{CF}, \mathrm{C}, \mathrm{FE}, \mathrm{EF}, \mathrm{E}, \mathrm{FClob}, \mathrm{ClobF}, \mathrm{Clob}$ (determinants); $\mathrm{A},(\mathrm{A}), \mathrm{Ad},(\mathrm{Ad}), \Sigma \mathrm{A}, \mathrm{H},(\mathrm{H}), \mathrm{Hd},(\mathrm{Hd}), \Sigma \mathrm{H}, \mathrm{Anat}, \mathrm{Sex}, \mathrm{Sg}$, Bot, Geo, Nat, Pais, Obj, Arq, Art, Simb, Abst, Elem, Frag (content); Ban (banalities).

2. A simple linear regression model was used to verify the potential effects of sex, age, and school system in the results obtained by the adolescents in the Rorschach psychodiagnostic test (to investigate the effect of only one of 
these factors on the Rorschach dependent variables) and then an adjusted multiple model was applied (to assess potential effects of the interactions among sex, age, and school system). The variables associated with location, determinants, content and banalities were examined in their relative proportions in regard to the total number of responses to the protocol (R), considering the binomial distribution of results.

\section{Ethical Considerations}

This study was submitted to and approved by the Institutional Review Board at the Faculdade de Filosofia, Ciências e Letras de Ribeirão Preto of the Universidade de São Paulo (CEP-FFCLRP Protocol no. 347/2007 2007.1.1888.59.3). The researchers implemented ethical and technical guidelines necessary to ensure work progress and to guarantee the rights of the participants and their freedom to choose whether to participate or not in the study.

\section{Results}

Given the multiplicity of Rorschach variables (Parisian School), we opted to present descriptive data together with the inferential analysis, though with specific highlights for the interpretation of findings.

Table 2

Descriptive and Inferential Results of Adolescents $(N=180)$ in Rorschach variables (Parisian School)

\begin{tabular}{|c|c|c|c|c|c|c|c|}
\hline Variables & $M d n$ & $M$ & $S D$ & $M(\%)$ & Minimum & Maximum & $\begin{array}{l}\text { Statistically significant differences between } \\
\text { subgroups in this study }\end{array}$ \\
\hline $\mathrm{R}$ & 15.5 & 17.7 & 8.4 & - & 7.0 & 49.0 & Publ $>$ Priv \\
\hline RA & - & 0.57 & 1.3 & - & - & 13.0 & - \\
\hline Rec & - & 0.46 & 0.9 & - & - & 4.0 & $\mathrm{M}>\mathrm{F}$ \\
\hline Den & - & 0.13 & 0.4 & - & - & 2.0 & - \\
\hline $\mathrm{TLm}^{\mathrm{a}}$ & 18.4 & 21.2 & 17.0 & - & 18.4 & 97.0 & - \\
\hline $\mathrm{TRm}^{\mathrm{a}}$ & 33.7 & 35.5 & 19.9 & - & 33.7 & 131.1 & $17>16>15$ \\
\hline G & 6.0 & 6.2 & 3.1 & 35.0 & 1.0 & 18.0 & $\mathrm{M}>\mathrm{F}$; Priv $>$ Publ \\
\hline $\mathrm{D}$ & 5.0 & 5.9 & 3.6 & 33.4 & - & 20.0 & $\mathrm{~F}>\mathrm{M}$ \\
\hline Dd & 4.0 & 5.3 & 4.7 & 30.3 & - & 24.0 & $\mathrm{~F}>\mathrm{M}$ \\
\hline Dbl & - & 0.2 & 0.5 & 1.1 & - & 3.0 & - \\
\hline $\mathrm{Di}$ & - & - & - & - & - & - & - \\
\hline $\mathrm{F}+$ & 5.0 & 5.3 & 3.2 & 30.2 & - & 17.0 & $\mathrm{M}>\mathrm{F}$ \\
\hline $\mathrm{F}+-$ & - & - & 0.2 & 0.2 & - & 2.0 & - \\
\hline F- & 3.0 & 4.2 & 3.7 & 24.0 & - & 21.0 & - \\
\hline$\Sigma \mathrm{F}$ & 9.0 & 9.6 & 6.1 & 54.5 & - & 30.0 & $\mathrm{M}>\mathrm{F} ;$ Publ $>$ Priv \\
\hline K & 0.5 & 0.8 & 1.1 & 4.8 & - & 6.0 & F $>$ M; Priv $>$ Publ; $17>16>15$ \\
\hline Kan & 1.0 & 1.4 & 1.7 & 8.2 & - & 11.0 & Priv $>$ Publ \\
\hline Kob & - & 0.1 & 0.2 & 0.6 & - & 2.0 & $16>15>17$ \\
\hline $\mathrm{Kp}$ & - & 0.1 & 0.5 & 0.9 & - & 4.0 & - \\
\hline$\Sigma \mathrm{k}$ & 1.0 & 1.7 & 1.9 & 9.8 & - & 12.0 & Priv $>$ Publ \\
\hline $\mathrm{FC}$ & 2.0 & 2.1 & 1.9 & 12.2 & - & 12.0 & - \\
\hline $\mathrm{CF}$ & 1.0 & 1.9 & 1.9 & 11.1 & 0.9 & 9.0 & $15>17>16$ \\
\hline $\mathrm{C}$ & - & - & 0.2 & 0.3 & - & 11.0 & - \\
\hline $\mathrm{FE}$ & - & 0.4 & 0.7 & 4.1 & - & 4.0 & $17>16>15$ \\
\hline $\mathrm{EF}$ & - & 0.7 & 1.0 & 2.6 & - & 6.0 & - \\
\hline $\mathrm{E}$ & - & - & 1.0 & 0.1 & - & 2.0 & - \\
\hline FClob & - & - & 1.0 & 0.1 & - & 2.0 & - \\
\hline ClobF & - & - & - & - & - & - & - \\
\hline Clob & - & - & - & 0.03 & - & 1.0 & - \\
\hline A & 6.0 & 6.7 & 3.7 & 37.9 & 1.0 & 21.0 & $15>16>17$ \\
\hline (A) & - & 0.6 & 0.9 & 3.7 & - & 5.0 & - \\
\hline
\end{tabular}




\begin{tabular}{|c|c|c|c|c|c|c|c|}
\hline Variables & $M d n$ & $M$ & $S D$ & $M(\%)$ & Minimum & Maximum & $\begin{array}{l}\text { Statistically significant differences between } \\
\text { subgroups in this study }{ }^{\mathrm{b}}\end{array}$ \\
\hline $\mathrm{Ad}$ & - & 1.4 & 1.8 & 8.2 & - & 10.0 & - \\
\hline (Ad) & - & 0.1 & 0.4 & 1.0 & - & 2.0 & - \\
\hline$\Sigma \mathrm{A}$ & 8.0 & 9.0 & 4.8 & 51.0 & 1.0 & 27.0 & $15>17>16$ \\
\hline $\mathrm{H}$ & 1.0 & 1.5 & 1.5 & 8.5 & - & 7.0 & $16>17>15$ \\
\hline (H) & - & 0.6 & 0.8 & 3.8 & - & 3.0 & - \\
\hline $\mathrm{Hd}$ & 1.0 & 1.3 & 1.6 & 7.5 & - & 8.0 & - \\
\hline (Hd) & - & 0.1 & 0.4 & 0.9 & - & 2.0 & - \\
\hline$\Sigma \mathrm{H}$ & 3.0 & 3.7 & 2.9 & 20.9 & - & 18.0 & $16>17>15$ \\
\hline Anat & - & 0.9 & 1.3 & 5.2 & - & 7.0 & Publ $>$ Priv \\
\hline $\mathrm{Sg}$ & - & - & 0.2 & 0.3 & - & 2.0 & - \\
\hline Sex & - & 0.1 & 0.4 & 0.5 & 1.0 & 3.0 & Priv $>$ Publ; $17>15>16$ \\
\hline Obj & - & 1.4 & 1.8 & 8.3 & - & 9.0 & - \\
\hline Art & - & 0.1 & 0.3 & 0.6 & - & 2.0 & - \\
\hline Arq & - & 0.2 & 0.5 & 1.1 & - & 4.0 & Priv $>$ Publ \\
\hline Simb & - & 0.2 & 0.5 & 1.1 & - & 4.0 & - \\
\hline Abs & - & - & 0.3 & 0.4 & - & 3.0 & - \\
\hline Bot & - & 0.6 & 0.9 & 3.7 & - & 5.0 & $15>16>17$ \\
\hline Geo & - & 0.4 & 0.9 & 2.6 & - & 5.0 & $M>F$ \\
\hline Nat & - & - & 0.2 & 0.2 & - & 1.0 & - \\
\hline Pais & - & 0.1 & 0.4 & 0.9 & - & 3.0 & $16>17>15$ \\
\hline Elem & - & 0.1 & 0.4 & 0.8 & 1.0 & 3.0 & - \\
\hline Frag & - & 0.3 & 0.7 & 1.7 & - & 4.0 & Publ $>$ Priv \\
\hline Ban & 3.0 & 3.0 & 1.4 & 17.0 & - & 7.0 & Priv $>$ Publ \\
\hline
\end{tabular}

Note. ${ }^{\mathrm{a}}$ Expressed in seconds. ${ }^{\mathrm{b}}$ Subgroups of adolescents: $\mathrm{Publ}=$ Public schools; Priv $=$ Private schools; $\mathrm{M}=\mathrm{Male} ; \mathrm{F}=\mathrm{Female} ; 15=15$ years old; $16=16$ years old; $17=17$ years old

In terms of Rorschach productivity, the adolescents presented an appropriate average number of responses $(\mathrm{R}=$ 17.7), accompanying parameters considered to be typical in the field's scientific literature. We also verified rapidity in the reaction processes and elaboration of responses in the cards, which were examined by verifying the mean elapsed time (TLm) and mean response time (TRm). Additional responses (RAs), refusals, and denials were not expressive, indicating that the adolescents did not experience important emotional impact in the face of stimuli, which would have altered the task's productive possibilities.

Analysis of the location of responses revealed a predominance of global responses $(\mathrm{G}=35.0 \%)$, followed by Detail responses $(\mathrm{D}=33.4 \%)$ and finally, by Small Detail (Dd $=30.3 \%$ ) responses. In this way, each mode of apperception achieved about one third of the responses identified among the adolescents. Location on the white background (Dbl) was little used by the participants (1.1\%); Di location (inhibitory detail) was not verified among the responses. These indexes indicate a tendency, on the part of the participants, for an initially global apperception of reality, accompanied by attention to practical and relevant elements of the context, including an analysis of the environment's intricacies.
In regard to the determinants, more than half of the responses provided by the adolescents were reported as determined solely by stimuli's formal aspects $(\mathrm{F}=54.5 \%)$. Next, the determinants of the responses associated with color (23.6\%), movement (14.6\%) and shading (6.7\%) appeared. Such a result indicates that the adolescents presented reasonable manifestation of affective and imaginative elements in their responses, focusing, however, on the stimuli's formal elements.

The analysis of responses determined only by the form, still in comparison to the total number of responses, though focusing on formal quality $(\mathrm{F}+, \mathrm{F}+-, \mathrm{F}-)$, indicated a predominance of responses coded as $\mathrm{F}+(30.2 \%)$, followed by F- $(24.0 \%)$ and then, an inexpressive number of coding $\mathrm{F}+/$ $(0.2 \%)$. In turn, the structural indexes of Rorschach Parisian School, linked to the general level of the accuracy of logical analyses $(\mathrm{F}+\%$ and $\mathrm{F}+\mathrm{ext} \%)$, reached the following values: $\mathrm{F}+\%=55.6$ and $\mathrm{F}+\mathrm{ext} \%=57.3$. These indexes signaled reasonable formal adequacy and perceptive accuracy in the responses provided by the adolescents, since these values are similar to those found by Pasian (2000) for adults $(\mathrm{F}+\%=58.5$ and $\mathrm{F}+\mathrm{ext} \%=66.6$, respectively). The proportion between 
responses of positive $(\mathrm{F}+)$ and negative $(\mathrm{F}-)$ formal quality indicated reasonable perceptive accuracy of reality on the part of the adolescents, despite their commitment and effort to learn reality using primarily reason and thinking $(\mathrm{F} \%=54.5)$; here the table of formal quality by Pasian (2000) was used.

In regard to the determinants related to movement, there was a predominance of small synesthesia over large synesthesia $[(\mathrm{kan}+\mathrm{kob}+\mathrm{kp}=9.8 \%)>(\mathrm{K}=4.8 \%)]$. Data indicate that internal resources focused on imagination and creation are still developing (predominance of small synesthesia), which matches the period of development of the study's participants.

In regard to the determinants associated with color, again proportional to the total of responses $(N=3,191)$, a predominance of FC (12.2\%) on CF $(11.1 \%)$ and C $(0.3 \%)$ was found. There was however, a considerable frequency of $\mathrm{CF}$ responses when compared to FC responses, suggesting that aspects related to the adolescents' affectivity may manifest as failures in rational control, without however, characterizing emotional imbalance, indexes that are also compatible with the period of adolescence.

Finally, the responses determined by the cards' shading elements were not very frequent. Again, the responses primarily determined by form and secondly by shading (coding FE $=4.1 \%$ ), overlapped EF $(2.6 \%)$ and $\mathrm{E}(0.1 \%)$ responses, suggesting suitable logical continence of potential distressful experiences.

In regard to the distribution of content in the set of answers, there was a clear predominance of animal content $(\mathrm{A} \%=51.0 \%)$, followed by human content $(\mathrm{H} \%=20.9)$, totaling $71.9 \%$ of the responses produced by the participants. It follows therefore, that there will be a concentration of theoretically expected content $(\mathrm{A} \%+\mathrm{H} \%)$, however, with room for diversified interpretations $[(\mathrm{A} \%+\mathrm{H} \%)<75 \%]$. This complementary diversity of content, as shown, was associated with responses of object content (8.3\%), including the subcategories of food, mask and clothing, anatomical $(5.2 \%)$, botanical $(3.7 \%)$, geographic $(2.6 \%)$ and fragmented $(1.7 \%)$, that is content that is not very developed, which somehow, signalizes distressful experiences. The remaining content presented frequency close to $1.0 \%$ of the total of responses, therefore, is not expressive in terms of collective interests for the adolescents' age range.

The analysis of the subclasses of animal and human responses revealed a predominance of intact percepts $[A,(A)$, $\mathrm{H},(\mathrm{H})$ ], especially in the responses of animal content. Similar proportions of $\mathrm{H}(8.5 \%)$ and $\mathrm{Hd}(7.5 \%)$, however, suggest a search for constitution and integration of identity on the part of the students, a movement that is closely related to the period of adolescence in psychodynamic theoretical terms. It is important to note that the fact that the number of responses of animal content is much greater than that of human content suggests a certain immaturity in terms of contact with reality, since animal content is related to a more intuitive apperception and less cognitive and emotionally developed.

The last descriptive variable of the general profile of results obtained by the group of adolescents in the Rorschach test is the "banality" (Ban) response type. Of the total sample of responses, $17 \%$ were banal, indicating a similar level of participation in the collective level on the part of the participants, considering the normative parameter preliminarily (Pasian, 2000).
The analysis of the potential effect of sex, age, and school system on the codified variables of the Rorschach test is presented in Table 2 with the synthetic results of inferential statistical analyzes performed with the set of 54 variables of Rorschach Parisian School. A predominance of G over D and Dd responses, in addition to the high index of responses exclusively determined by form $(\mathrm{F} \%=54.5)$, was verified. The most frequent content was animal and human, accompanying theoretical estimates of identification with alive and dynamic elements from reality. It is worth noting, however, that these normative references should be cautiously analyzed, in order to enable valid and consistent interpretations.

This inferential statistical analysis conducted with the 54 variables presented by Rorschach enabled observing 26 variables with productive specificities according to sex, age or school system. This empirical evidence suggests that, in clinical practice, psychologists carefully examine these variables in which significant differences were recorded. Proper interpretation of Rorschach results should always be based on a set of variables and not only on isolated ones. They assume, therefore, clinical meanings more than as indicators of the need to develop normative references for subgroups of adolescents, taking into account the considerations discussed so far in this paper.

It is important to note that this initial description of results enables us to observe, more broadly, some general guidelines concerning the production of adolescents aged from 15 to 17 years old in response to Rorschach testing (Parisian School). After this initial analysis of results (related to locations, determinants, and content), we considered presenting the proportions among the variables of the Rorschach Method associated with emotional experience to be relevant. Table 3 presents these data based on affective formulas of the Parisian School, namely: Type of Intimate Resonance (TRI) first affective formula that expresses the relationship between human synesthesia and color responses; Latent Tendencies (TL - Complementary Formula FC) - second affective formula that expresses the relationship between non-human synesthesia and shading responses; and the Third formula (Reactivity to color $=\mathrm{RC}$ ), which expresses the relationship between number of responses provided to inkblot cards (VIII, IX, X) in relation to the total number of responses.

Table 3

Distribution (in Simple Frequency and Percentage) of Adolescents $(N=180)$ according the Function of Affective Formulas of Rorschach Parisian School

\begin{tabular}{lrrrrrr}
\hline Affective formula & \multicolumn{2}{c}{ First $^{\mathrm{a}}$} & \multicolumn{2}{c}{ Second $^{\mathrm{b}}$} & \multicolumn{2}{c}{ Third $^{\mathrm{c}}$} \\
Affective type & \multicolumn{1}{c}{$f$} & \multicolumn{1}{c}{$\%$} & \multicolumn{1}{c}{$f$} & \multicolumn{1}{c}{$\%$} & \multicolumn{1}{c}{$f$} & $\%$ \\
\hline Extratensive & 143 & 79.4 & 80 & 44.4 & 38 & 21.1 \\
Introversive & 21 & 11.6 & 54 & 30.0 & 46 & 25.6 \\
Ambiguous & 3 & 1.6 & 3 & 1.6 & 96 & 53.3 \\
Coartative & 13 & 7.2 & 43 & 23.9 & - & - \\
TOTAL & 180 & 100.0 & 180 & 100.0 & 180 & 100.0 \\
\hline
\end{tabular}

Note. ${ }^{\text {antimate Resonance Type (TRI). }{ }^{b} \text { Latent tendecies (TL). }}$ 'Reactivity to color (RC), emotional reactivity. 
Analysis of the Intimate Resonance Type (TRI) yields the observation that the adolescents revealed to be predominantly extratensive (79.4\%). Hence, they presented an affective orientation with openness to the environment, favoring practical intelligence, focused on external reality, as well as occasional emotional instability, especially the pure extratensive types. These characteristics can be considered to be theoretically associated with expectations of affective functioning in this age range, since adolescents tend to signal an intense need for bonding with peers and others, and may experience important variations of mood, with a lower signalization of reflexive movements (which characterize the introversive type of affective experience).

Still focusing on the TRI analysis, we observed that the experiences of the introversive affective type marked the responses of few adolescents (11.6\% of the sample), suggesting that the marks of introspection and selfexamination did not seem to characterize this age range. The coartative types, in turn, are even a smaller proportion of the adolescents $(7.2 \%)$, showing that marks of affective restriction do not predominate at this point of life. The ambiguous type presented an inexpressive frequency in the set of results concerning affective experience styles (only three adolescents, representing 1.6\% of the sample).

The analysis of the Complementary Formula (FC), the second Affective Formula, also known as the Latent Tendencies Formula (TL), also indicated a predominance of the extratensive type (44.4\% of the adolescents), confirming the interpretative hypothesis previously identified in the TRI analysis. In other words, the adolescents showed that their affective resources were primarily associated with opening emotional manifestations in the environment, tending to favor interpersonal contact and potential affective labiality. The introversive type appeared in $30.0 \%$ of the adolescents as the second affective formula, slightly below the frequency of coartative types (present in $23.9 \%$ of the cases), suggesting enriched affective resources of reflection and complementary to the predominant style of affective experience. Again, the ambiguous type reached inexpressive frequency in the set of results concerning affective experience styles (only three adolescents).

Most of the adolescents (53.3\%) presented the ambiguous affective experience type in the Third Formula (RC), revealing equilibrium between the two types of experience (introversive and extratensive). Considering that the third formula may signify expectations in regard to the current time in life, this information reveals an important element related to a desire to adapt to the environment in an emotionally balanced way.

\section{Discussion}

As previously shown, it was possible to compare current data and that found in the sample of adolescents and young adults assessed by Azoulay et al. (2007) in France and that from adolescents assessed by Ikiz et al. (2010) in Turkey. It is important to keep in mind that these studies are the most recent works of a normative nature of the Rorschach Parisian School, which is internationally acknowledged.
In regard to the productivity of the Rorschach method, the adolescents in this study presented an average of 17.7 responses $(R=17.7)$, therefore, fewer than was found in the French $(\mathrm{R}=25.8)$ and Turkish $(\mathrm{R}=19.0)$ studies. It was possible, however, to perceive in the three studies that card $\mathrm{X}$ is the one that elicits the greater number of associations. According to Azoulay et al. (2007), this finding may be related to the multiplicity of colors and dispersion of the inkblot, which enable greater perceptive activity.

Still considering the productivity of Rorschach testing, the additional responses, refusals and denials, which indicate emotional impact in the face of Rorschach stimuli, were infrequent in comparison to the total of responses. The adolescents in this study presented an average of 0.46 refusals, while the adolescents and young adults in France (Azoulay et al., 2007) presented an average of 0.18 refusals, and the Turkish adolescents presented an average result of 0.59 refusals (Ikiz et al., 2010). The analysis of refusals showed that cards IV and VI received the most relevant reaction among Brazilian adolescents, which can be also found in the studies of Anzieu (1970/1986) and Rausch de Traubenberg (1970/1998). In the studies conducted by Azoulay et al. and Ikiz et al., cards IX and II generated a higher number of refusals. In turn, card I and V were those with the lowest number of rejections in the three normative studies of the Rorschach method.

In regard to modes of apperception, some peculiarities were observed in the three studies previously mentioned and compared. Verifying the results obtained with Brazilian adolescents, the average proportions of G, D and Dd responses were very similar $(35.0 \%, 33.4 \%$, and $30.3 \%$, respectively). Indexes of $\mathrm{G}=43.3 \%, \mathrm{D}=43.6 \%$ and $\mathrm{Dd}=10.2 \%$ were found in the French study, therefore, showing similarity in the number of responses classified as G and D. Among Turkish adolescents, however, the number of responses classified as D $(66.0 \%)$ was larger, while the responses in $\mathrm{G}$ and Dd presented $28.1 \%$ and $3.4 \%$, respectively. These results indicate that, among Brazilian and French adolescents, an important number of associations were made based on a general perception of stimuli (responses G), performing a more generalist, and perhaps, a more superficial analysis of stimuli, with reduced elaboration of thought.

In the face of this type of evidence, Azoulay et al. (2007) wondered whether this increased number of $G$ responses in comparison to $\mathrm{D}$ responses could be related to a passive attitude of young individuals in response to a context saturated with visual information, implying a lower susceptibility to discrimination and selection of data. They also stated they had captured this tendency to increased global responses to Rorschach tests in studies conducted in other countries. Another aspect requiring explanation is the high rate of Dd responses among Brazilian adolescents, suggesting a potential thoroughness and attention to small details, which may result in an analytical strategy to deal with the complex existing reality. This greater proportion of Dd and lower proportion of D found in Brazil, however, may hinder appropriate connection to relevant elements of the context, due to an excessive attention to details, 
generating analyses permeated with logical immaturity. These hypotheses, however, could not be properly tested or demonstrated, given the findings' observational nature, without a typical experimental design. Thus, understanding that these peculiarities in the Rorschach production are useful elements in the process of interpreting cases remains, specifically in adolescence, both in France and Brazil.

Still in regard to other modes of apperception of stimuli, the reduced number of $\mathrm{Dbl}$ responses, that is, demarcated in the Rorschach cards' white background, was verified in the studies conducted in the three countries. This study conducted in Brazil showed a proportion of $1.1 \%$ of responses, while in Turkey (Ikiz et al., 2010) this index reached $2.0 \%$ of Rorschach interpretations. In France, however, even though this is also the mode of apperception less frequently used, there was an occurrence of $9.2 \%$ of responses located in $\mathrm{Dbl}$ areas. These data may suggest marks of a more critical psychological functioning on the part of the French, which would deserve a proper empirical investigation to support. The low expressiveness of this technical indicator in relation to the set of data, limits its interpretative value as a whole. We can only say, that in general, the adolescents addressed in this study were not very willing to observe Rorschach stimuli focusing on the background (white), paying attention to the figure itself (inkblots), marking a reduced oppositionist tendency in their analyzes of reality. It also appeared to have happened in the other groups assessed Azoulay et al. (2007) and by Ikiz et al. (2010).

In regard to the responses with purely formal determinants, the opposing results of the three studies at this point present a relatively important difference. The average percentage presented here for the formal determinant $(\mathrm{F} \%)$ was of $54.5 \%, 55.6 \%$ for $\mathrm{F}+\%$, and $57.3 \%$ for $\mathrm{F}+\operatorname{ext} \%$. Azoulay et al. found average values corresponding to $61.3 \%$, $65.2 \%$ and $66.0 \%$, respectively, while Ikiz et al. found that $\mathrm{F} \%=62.0 ; \mathrm{F}+\%=76.5$ and $\mathrm{F}+\mathrm{ext} \%=77.2$. These data indicate that the adolescents in the three contexts tried to keep control of affective content, resorting to the stimuli's formal elements, though less frequently than those in the Brazilian context. This tendency of the adolescents addressed in this study could be considered a resource of greater spontaneity in the interpretation of reality, as well of a greater projection of effective and imaginative elements, compared to the individuals in France and Turkey. Therefore, specific standards of rational investment to respond to Rorschach tests were observed, indicating the typical involvement of individuals of that group to interpret their environment, suggesting the sensitivity of this projective method to capture peculiarities of human development in varied contexts, once more justifying regional investigations of these patterns of responses to the instrument.

In regard to the content of Rorschach interpretations, a prevalence of animal $(\mathrm{A}=51.0 \%)$ and human $(\mathrm{H}=20.9 \%)$ content was verified among the adolescents assessed here. The same occurred with the studies conducted in France and Turkey, in which the average percentages were: $\mathrm{A}=$ $44.5 \%$ and $\mathrm{H}=16.0 \%$ in France; $\mathrm{A}=41.0 \%$ and $\mathrm{H}=13.7 \%$ in Turkey. These results indicate that, despite considerable frequency of animal and human content, the adolescents made associations and interpretations with other content, suggesting a diversity of interest and richness in their contact with the environment. Another four category of content, also present in this study, deserved to be highlighted, namely: Object (8.3\%); Anatomic (5.2\%); Botanic (3.7\%); and Geographic (2.6\%). That is, the adolescents also expressed signs that suggest interest for content that reveals experience of certain distress, perhaps marking their stage of development. The remaining Rorschach content reached very low average proportions, below $1 \%$ of responses, not expressing consistent data for an analysis of a normative nature, except in relation to its low incidence.

In regard to the types of affective experience, Azoulay et al. (2007) and Ikiz et al. (2010) report only the results of the Rorschach Third Formula (Reactivity to color $=\mathrm{RC} \%$ ). The values found in this affective Third Formula were: $\mathrm{RC} \%=35.0$ for the adolescents addressed in this study; $\mathrm{RC} \%=34.6 \%$ for the French adolescents and $\mathrm{RC} \%=37.0$ for the Turkish adolescents. Therefore, the adolescents of the three contexts presented an experience, based on the Rorschach Third Formula, classified as ambiguous, revealing the presence of introspective and reflexive resources, as well as the need for contact and proximity with the external world. This is, therefore, another indicator that suggests a resource on the part of the adolescents in contact with themselves and the environment: interest and flexible affective sensitivity susceptible to varied manifestation depending on the external context.

In the face of the possibility of using the Rorschach method in different contexts and with populations of different ages, the data presented here reveal the importance of conducting normative studies with specific populations. In this sense, Pasian and Loureiro (2010) point out that the assessment of the results of individuals in a psychological assessment instrument, in this case a Rorschach test, needs to be transformed into a relative measure (technical indicators), obtained with groups of individuals to enable the verification of the relative position of the individual within the group, as well as to compare the production of individuals in different assessment techniques. Hence, norms enable locating the performance of an individual in a distribution of a group that is considered to be a reference.

In this sense, Resende and Argimon (2010) also discuss the assertion of Weiner (1998/2000) that the Rorschach method would be a universal instrument possible to be used in different cultures. The argument used by these authors involves the idea of considering culture as an aspect of the context for the functioning of personality, but not an exclusive determinant of its structure and dynamics. Hence, personality would be, under this view, a universal phenomenon. They defend the view that professionals using Rorschach tests should keep in mind that this instrument, at the same time as it enables accessing characteristics of personality that are universally applied, also reveals peculiarities that are inherent to the individuals' context of life. Therefore, the psychological functioning of these individuals, as well as their respective personal adaptation skills, demand analysis within their specific social, educational, occupational, family and interpersonal contexts. Therefore, even though 
Rorschach testing is considered a method that is free from culture, it is also sensitive to cultural differences because it captures the modes of expression inherent to the individuals, which demands familiarity of the evaluator with the culture of that specific individual being assessed in order to seek an appropriate interpretation of the test (Nascimento, 2010). The relevance of studies with the objective to develop normative references of the Rorschach method per regions and specific stages of human development, therefore follows.

Resende and Argimon (2010) also discuss normative studies, stressing that these studies should be regularly conducted, because globalization tends to weaken popular traditions, generating increased modernization with its respective implications, such as expressive demographic changes and multi-acculturation, elements that reflect on the results obtained by individuals in psychological assessment instruments.

Specifically in relation to Brazil, Pasian and Loureiro (2010) stress that obtaining representativeness of Rorschach normative studies is critical, since it refers to a country of continental proportions, which implies significant cultural diversity among the population. Therefore, the authors recognize the technical limitations of the studies available, which to be feasible address convenience samples, as well as the impossibility of generalizing results in a way that enables different sociocultural contexts to be considered in psychological assessment processes. They highlight, however, the importance of studies of this nature and encourage researchers for the various regions in the country to work on multi-center studies to help improve the work of the professionals involved in the field of psychological assessment in Brazil, since these professionals frequently refer to results reported in research to base their professional practice.

\section{References}

Anzieu, D. (1986). Os métodos projetivos [The projective methods] (M. L. E. Silva, Trans., 5th ed.). Rio de Janeiro, RJ: Campus. (Original work published 1970)

Azoulay, C., Emmanuelli, M., Rausch de Traubenberg, N., Corroyer, D., Rozencwajg, P., \& Savina, Y. (2007). Les données normatives françaises du Rorschach à l'adolescence et chez le jeune adulte [The French normative data of Rorschach in adolescents and young adults]. Psychologie Clinique et Projective, 13(1), 371409. doi:10.3917/pcp.013.0371

Brando, M., Valera, J. M., \& Zarate, Y. (2008). Estilos de apego y agresividad en adolescentes [Attachment styles and aggressiveness among adolescentes]. Psicología, 27(1), 16-42. Retrieved from http://www.ucv.ve/organizacion/ facultades/facultad-de-humanidades-y-educacion/escuelas/ psicologia/documentacion-y-publicaciones/publicaciones/ psicologia-revista-de-la-escuela-de-psicologia.html

Carvalho, R. G., \& Novo, R. F. (2014). The relationship between structural dimensions of personality and school life in adolescence. Psicologia: Reflexão e Crítica, 27(2), 368-376. doi:10.1590/1678-7153.201427218

Chagnon, J.-Y. (2013). L'École de Paris: Bref historique [The Parisian school: Brief history]. Le Carnet Psy, 169(2), 27-
29. doi:10.3917/lcp.169.0027

Conselho Federal de Psicologia. (2010). Avaliação psicológica: Diretrizes na regulamentação da profissão [Psychological assessment: Guidelines for the profession regulation]. Brasília, DF: CFP.

Chabert, C. (2004). Psicanálise e métodos projetivos [Psychoanalysis and projective methods] (A. J. Lelé \& E. M. A. C. Silva, Trans.). São Paulo, SP: Vetor. (Original work published 1998)

Fensterseifer, L., \& Werlang, B. S. G. (2008). Apontamentos sobre o status científico das técnicas projetivas [Notes on the scientific status of projective techniques]. In A. E. Villemor-Amaral \& B. S. G. Werlang (Orgs.), Atualizações em métodos projetivos para avaliação psicológica [Updates on projective methods for psychological assessment] (pp. 15-33). São Paulo, SP: Casa do Psicólogo.

Hisatugo, C. L. C., \& Yazigi, L. (2014). Estudo exploratório com indivíduos com depressão por meio do Rorschach, Sistema Compreensivo [An exploratory study in patients with depression by the Rorschach Comprehensive System].Avaliação Psicológica, 13(2), 157-166. Retrieved from http://pepsic.bvsalud.org/scielo.php?script=sci_ abstract\&pid $=$ S1677-04712014000200003\&lng=pt\&nr $\mathrm{m}=\mathrm{iso} \& \operatorname{tn} \mathrm{g}=\mathrm{pt}$

Ikiz, T. T., Zabci, N., Dusgor, B. P., Atak, I. E., Yavuz, E., Purisa, S., \& Catagy, P. (2010). Étude normative du Rorschach de la population adolescente turque [Normative Rorschach data of the Turkish adolescent population]. Psychologie Clinique et Projective, 16(1), 209-232. doi:10.3917/ pcp.016.0209

Jordão, A. B., \& Ramires, V. R. R. (2010). Vínculos afetivos de adolescentes borderline e seus pais [Affective bonds between borderline adolescents and their parentes]. Psicologia: Teoria e Pesquisa, 26(1), 89-98. doi:10.1590/ S0102-37722010000100011

Knobel, M. (1981). Síndrome da adolescência normal. [Syndrome of normal adolescence] In A. Aberastury \& M. Knobel, Adolescência normal: Um enfoque psicanalítico [Normal adolescence: A psychoanalytic approach] (S. M. G. Ballve, Trad., pp. 24-62). Porto Alegre, RS: Artes Médicas.

Lis, A., Salcuni, S., \& Parolin, L. (2007). Rorschach Comprehensive System data for a sample of 116 preadolescent and 117 adolescent nonpatients from Italy. Journal of Personality Assessment, 89(Suppl 1), S91-S96. doi:10.1080/00223890701583259

Meyer, G. J., Erdberg, P., \& Shaffer, T. W. (2007). Toward international normative reference data for the comprehensive system. Journal of Personality Assessment, 89(Suppl 1), S201-S216. doi:10.1080/00223890701629342

Meyer, G. J., Viglione, D. J., Mihura, J. L., Erard, R. E., \& Erdberg, P. (2011). Rorschach Performance Assessment System: Administration, coding, interpretation, and technical manual. Toledo, OH: Rorschach Performance Assessment System. 
Mihura, J. L., Meyer, G. J., Dumitrascu, N., \& Bombel, G. (2013). The validity of individual Rorschach variables: Systematic reviews and meta-analyses of the comprehensive system. Psychological Bulletin, 139(3), 548-605. doi:10.1037/a0029406

Nascimento, R. S. G. F. (2010). Sistema compreensivo do Rorschach: Teoria, pesquisa e normas para a população brasileira [Comprehensive system of Rorschach: Theory, research and norms for Brazilian population]. São Paulo, SP: Casa do Psicólogo.

Outeiral, J. O. (1994). Adolescer: Estudos sobre adolescência [Adolescent: Studies of adolescence]. Porto Alegre, RS: Artes Médicas.

Paladino, E. (2005). O adolescente e o conflito de gerações na sociedade contemporânea [The teenager and the conflict of generations in contemporary society]. São Paulo, SP: Casa do Psicólogo.

Pasian, S. R. (2000). O psicodiagnóstico de Rorschach em adultos: Atlas, normas e reflexões [The psychodiagnostic of Rorschach in adults: Atlas, norms and reflections]. São Paulo, SP: Casa do Psicólogo.

Pasian, S. R., \& Loureiro, S. R. (2010). Reflexões sobre princípios e padrões normativos do Rorschach [Reflections on the principles and normative standards of Rorschach]. In S. R. Pasian (Org.), Avanços do Rorschach no Brasil [Advances of Rorschach in Brazil] (pp. 30-54). São Paulo, SP: Casa do Psicólogo.

Primi, R. (2010). Avaliação psicológica no Brasil: Fundamentos, situação atual e direções para o futuro [Psychological Assessment in Brazil: Foundations, current situation and future directions. Special number]. Psicologia: Teoria e Pesquisa, 26, 25-35. doi:10.1590/ S0102-37722010000500003

Rausch de Traubenberg, N. (1998). A prática do Rorschach [The practice of Rorschach] (A. J. Lelé, Trans.). São Paulo, SP: Vetor. (Original work published 1970)

Resende, A. C., \& Argimon, I. I. L. (2010). Perspectiva transcultural do método de Rorschach [Cross-cultural perspective of Rorschach]. In S. R. Pasian (Org.), Avanços do Rorschach no Brasil [Advances of Rorschach in Brazil] (pp. 87-119). São Paulo, SP: Casa do Psicólogo.

VanPatten, K., Shaffer, T.W., Erdberg, P., \& Canfield,M.(2007). Rorschach Comprehensive System data for a sample of 37 nonpatient/nondelinquent adolescents from the United States. Journal of Personality Assessment, 89(Suppl 1), S188-S192. doi:10.1080/00223890701583507

Viglione, D. J., Meyer, G. J., Mihura, J. L., Erard, R., \& Erdberg, P. (2012). The Rorschach Performance Assessment System and advances in the Rorschach Method. In D. M. Amparo, E. T. K. Okino, F. Osório, C. L. C. Hisatugo, \& M. Tavares (Orgs.), Métodos projetivos $e$ avaliação psicológica: Atualizações, avanços $e$ perspectivas [Projective methods and psychological assessment: Updates, advances and perspectives] (pp. 102-125). Brasília, DF: ASBRo. Retrieved from http:// newpsi.bvs-psi.org.br/ebooks2010/pt/Acervo_files/ MetodosProjetiv-AvaliacPsi.pdf
Weiner, I. B. (2000). Princípios da interpretação do Rorschach [Principles of Rorschach's interpretation]. São Paulo, SP: Casa do Psicólogo. (Original work published 1998)

Yazigi, L. (2010). Fundamentação teórica do método de Rorschach [Theoretical fundamentation of Rorschach's method]. In S. R. Pasian (Org). Avanços do Rorschach no Brasil [Advances of Rorschach in Brazil] (pp. 7-29). São Paulo, SP: Casa do Psicólogo.

Maria Luísa Casillo Jardim-Maran is a Ph.D. in Psychology from Universidade de São Paulo and a Professor at the Centro Universitário de Franca.

Sonia Regina Pasian is a Professor at the Universidade de São Paulo.

Erika Tiemi Kato Okino is a Ph.D. and a Psychologist from Universidade de São Paulo.

Received: Apr. 9, 2015

1st Revision: June 11, 2015

Approved: July 21, 2015

How to cite this article:

Jardim-Maran, M. L. C., Pasian, S. R., \& Okino, E. T. K. (2015). Normative study of Rorschach (Parisian school) for Brazilian adolescents. Paidéia (Ribeirão Preto), 25(62), 333-342. doi:10.1590/1982-43272562201507 